ISSN: 1813-162X (Print) ; 2312-7589 (Online)
available online at: http://www.tj-es.com Tikrit Journal of Engineering Sciences

Asmaa Abdul Jabbar Jamel*
Civil Engineering Department
Tikrit University
Salahuddin Province
Iraq

Keywords:

Flow-3D

Artificial Neural Network

energy dissipation

stepped spillways

\section{Numerical Simulation for Estimating Energy Dissipation over Different Types of Stepped Spillways and Evaluate the Performance by Artificial Neural Network}

\author{
A B S T R A C T
}

In this research, Flow-3D software uses to study the energy dissipation for stepped spillways with different end sills. The study is bases on three models. The first model contains rectangular end sills in all steppes. The second model contains rectangular end sills between one step and another. The third model contains triangular end sills in all steppes. For each of these models, three different variables are adopt, slope, height of the spillway and a number of steppes, and four different discharges value, carrying the total number of experiments to (324) tests. Analytical results show that the model (3) is the highest energy dissipation for all discharges value. Empirical equations extraction to find the energy dissipation for each of these models. The artificial neural network is also adopt to prove the accuracy and efficiency of the analytical results which are at high rates of compatibility with the values of the coefficient of determination for (model 1), (model 2) and (model 3) equal to $(93.47 \%),(88.20 \%)$ and $(86.00 \%)$ respectively. Also, artificial neural network identifies the most influential factors on the energy dissipation, the friction Froude number is the highest impact on the energy dissipation for models (1) and (2), while the parameter (b/ks) for the model (1).

(C) 2018 TJES, College of Engineering, Tikrit University

DOI: http://dx.doi.org/10.25130/tjes.25.2.03

\section{A R T I C L E I N F O

\begin{tabular}{ll} 
Received & 14 October 2017 \\
Accepted & 03 January 2018 \\
Available online & 17 June 2018 \\
\hline
\end{tabular} \\ Article history:}

محاكاة عددية لتقدير تبديد الطاقة فوق أنواع مختلفة من المطافح المدرجة وتقييم أداعها عن طريق الثبكة العصبية الاصطناعية

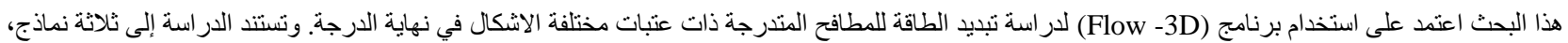

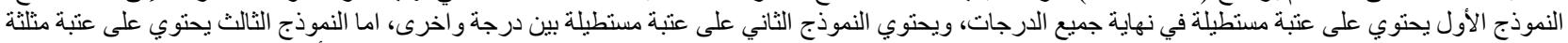

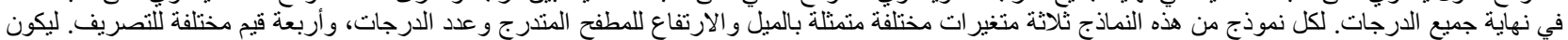

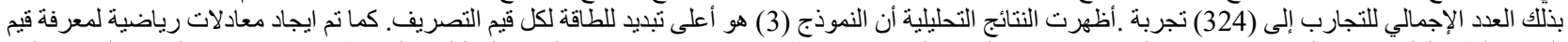

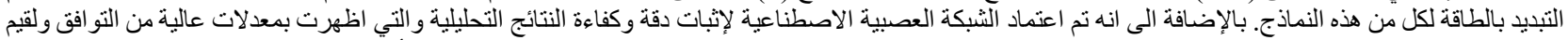

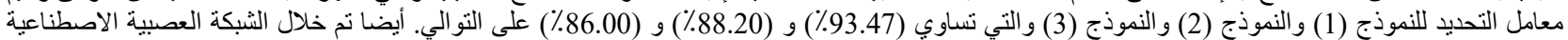

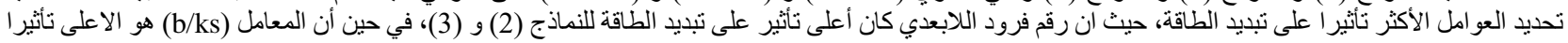

اللنموذج (1) (1)

\section{INTRODUCTION}

Stepped spillways are considered as hydraulic structures that have a significant effect in reducing erosion at the downstream of dams. The flow of water over the spillway to downstream leads to the conversion of the potential energy into kinetic energy so dissipate energy [1]. 
A number of researchers have conducted studies showing the extent of dissipation of energy for different types of these stepped spillways. Described the dissipation of energy for different number of steps showed that reducing the number of steps lead to increased energy dissipation $[2,3]$. Also numerical studied by using Flow-3D to show the effect of the number of steps and drainage on top of the stepped spillway on the energy dissipation which showed the proof of the inverse relation between the discharge rate and the dissipation of energy and the great software simulation for different cases [4-6]. Based on the use of both FLUENT and V-Flow to modeling the unstable twodimensional flow over the stepped spillway, results obtained by the FLUENT program for the energy dissipation for the stepped spillway showed a reasonable agreement in results [7-9]. Also, artificial neural network (ANN) and the techniques of gene expression used for modeling the experimental data of nappe and skimming flow over stepped spillways, so the results obtained from these techniques were at a reliable level in the prediction of the energy dissipation [10]. Laboratory experiments used to find the optimal height of the step and the best slope for energy dissipation through the application of several different models and the different flow systems represented by the skimming, transition and nappe flow by the calculation of energy dissipation of various models [11]. The distribution of pressure and the energy dissipation over traditional and semicircular crest studied to develop empirical equations for the amount of dispersion and pressure distribution of these models [12]. In addition, based on stepped spillways which have increased surface roughness to increase energy dissipation for various forms of steps, results showed the model with roughness increased the dispersion for both high and low discharge $[13,14]$. It was also based on the special geometry of steps shape for the spillways stepped, labyrinth or quarter circle geometry at step edges, these types of model achieved a percentage of energy gain dissipated $[15,16]$. Also used different configurations on the steps of the spillway and different end sills, which showed the high level of dissipation in different forms from the traditional type, and the elimination of air pockets $[17,18]$.

The aim of this research is to study the energy dissipation for stepped spillway using Flow-3D program, which involves the use of three different models of stepped spillway, represent by steps with end sills of rectangular, triangular sills, and a final model with a rectangular sills placed between one and other steps. The result of energy dissipation, then analyzes and empirical equations determine. Also the efficacy of these results is demonstrate by using the artificial neural network.

\section{FLOW-3D PROGRAM}

Flow-3D is a computational fluid dynamics software produced by Flow Science Inc., which practices both the VOF method for determining the position of the free surface and the FAVOR method for location of obstacles. The computational area is divide using a structured mesh and all relevant equations utilizes discrete the method of FV. The program contains several turbulence algorithms that permit for the solving of the RANS equations, most significantly, the RNG and K- $\varepsilon$ closure models and wall shear limit conditions; Non-slip or partial slip are use in this research. These closure algorithms are appropriate for the modeling of flow over spillways, due their appropriateness in cases where a large quantity of turbulence is creat which, in this case, is cause by the flow of the fluid over the control structure. Flow-3D advanced to solve the Navier-Stokes equations in three dimensions. Also, uses an orthogonal coordinate arrangement as opposed to a body fitted arrangement and can have a single network mesh block, relative linked mesh blocks, or a combination of network and linked mesh blocks.

\subsection{Model, Mesh Geometry and Boundary Conditions}

Performing experiments require drawing models of stepped spillways geometry into (Auto-CAD), then the geometry is import into Flow-3D in (STL) format.

The most important item to be observe in the modeling of the flow program is the determination of the computational grid, which depends mainly on the size of the specific domain and the number of cells that affect the run time and accuracy of the solution. Calculating the unknown values by division of the actual area of work into smaller and interconnected cells then calculate the value in the center of each cell. In this study the mesh size is (1.5 $\mathrm{cm})$ in all directions, as show in Fig. 1.

Fig. 2 shows boundary conditions of the models in all directions, where the water entrance is represented by drainage inlet $(\mathrm{Q})$ and the outlet of the water is represented by the discharge outlet $(\mathrm{O})$, the ground floor is a wall $(\mathrm{W})$ and the surface of the flow is the exhibition of atmospheric pressure $(\mathrm{P})$.

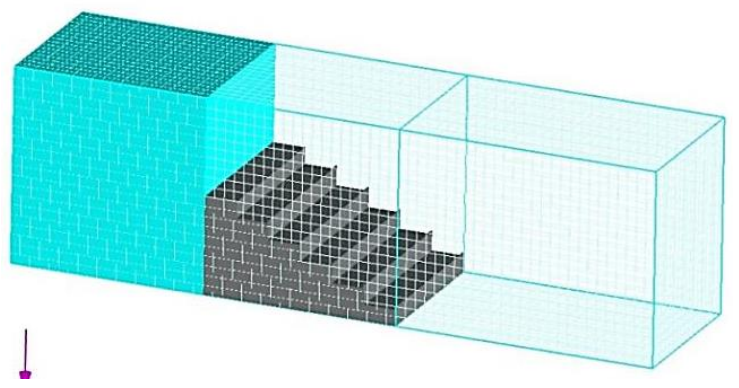

Fig. 1. Mesh geometry in this study.

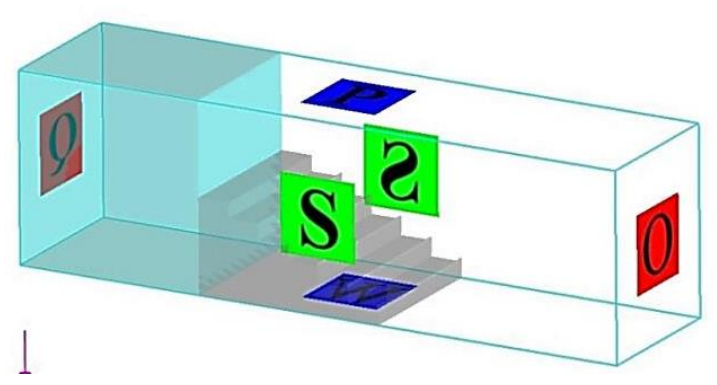

Fig. 2. Boundary condition in this study.

\subsection{Numerical Models Tests}

This study is conduct for three models. The model (1) is stepped spillway with rectangular sills at the end of each step, as for model (2) is similar to the same geometric 
dimensions of model (1) but the sills between steps and the other, while model (3) has the same geometric characteristics of the model (1) but replace the rectangular sills with triangular sills. As shown in Fig. 3.

Experiments are conduct for these three models using the height of the spillway $(H=15,20,25) \mathrm{cm}$. For each of these height, three slopes are use with values of $(S=$ $0.5,1,1.25)$, and three values for the number of steps $(N=$
$6,12,18) \mathrm{cm}$ with a constant width of the flume $(25 \mathrm{~cm})$ and sill dimension $(0.2 \times 0.5) \mathrm{cm}$. Thus, the model has $(27)$ different forms, the total number of tests for each model is (108), while the total number of tests for the three models are (324) tests. For each of these experiments, the amount of energy dissipation is extract. Fig. 4 shows output results with flow-3D.

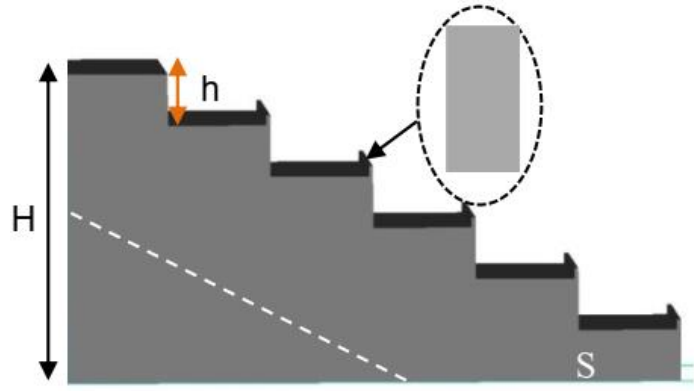

Fig.3-a. Model 1

(a) Model 1

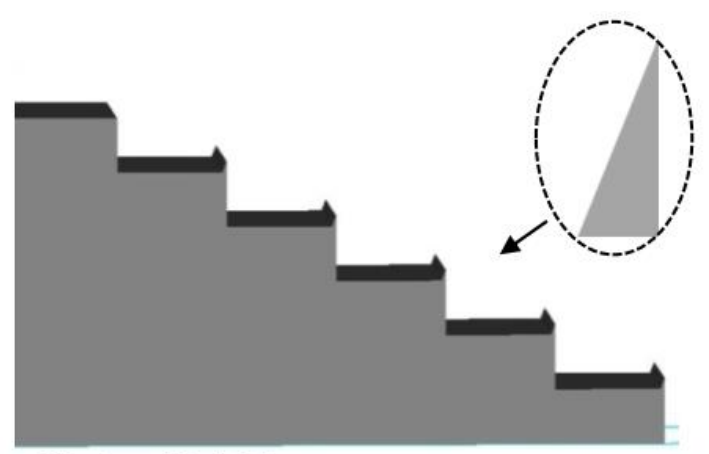

Fig.3-c. Model 3

(c) Model 3

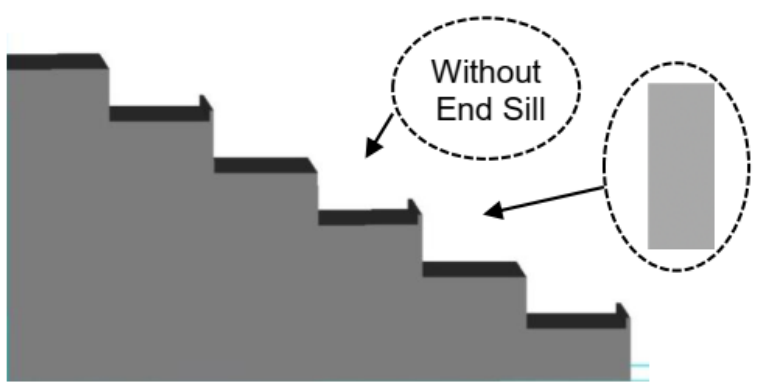

Fig.3-b. Model 2

(b) Model 2

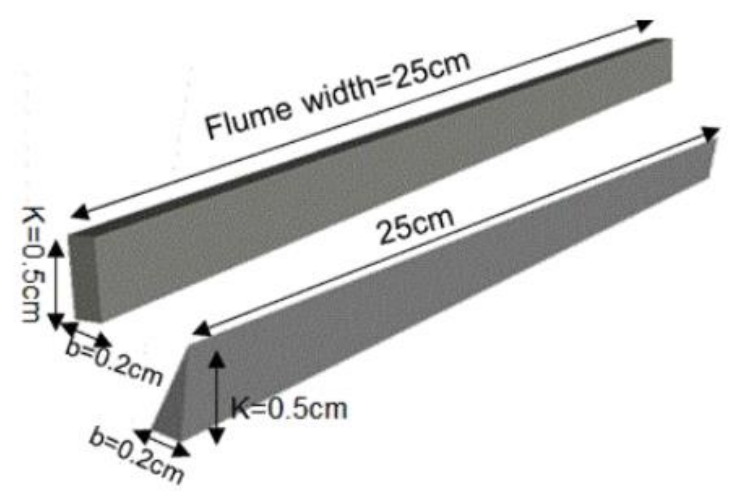

(d) Model end sills

Fig. 3. Stepped spillway physical model in this study.

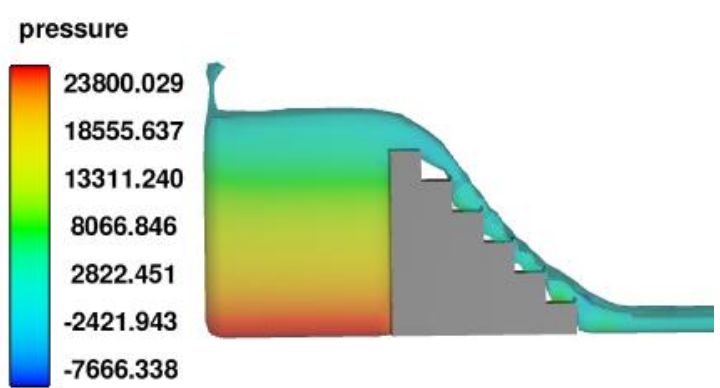

(a) Model 1, $H=20 \mathrm{~cm}, S=1.25, N=6$,

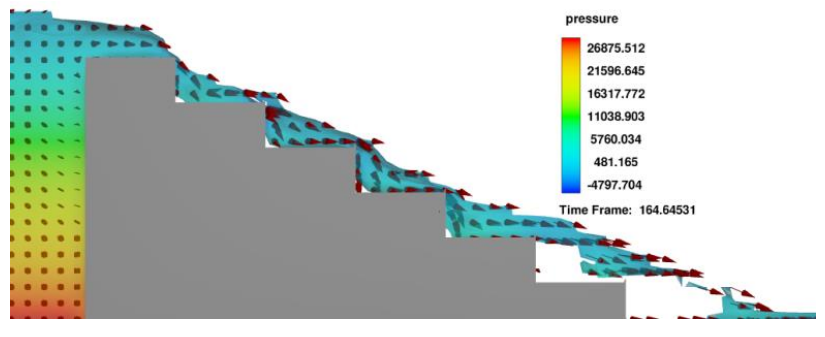

(c) Model 3, $H=25 \mathrm{~cm}, S=0.5, N=6$

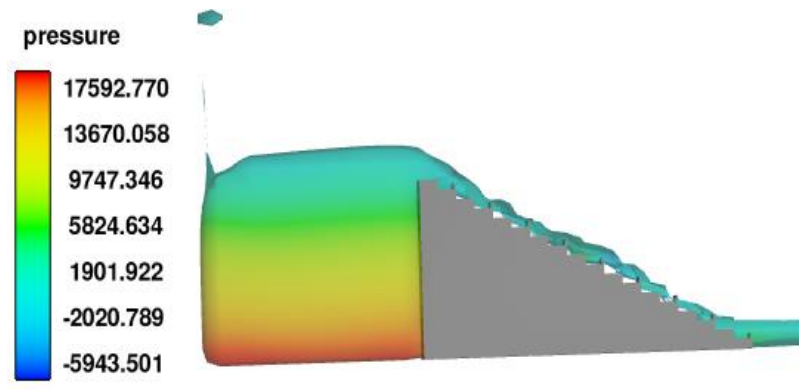

(b) Model 2, $H=15 \mathrm{~cm}, S=0.5, N=18$.

Fig. 4. Results of models for energy dispersion. 


\section{DIMENSIONAL ANALYSIS}

The variables that have been adopted in this study that will affect the amount of energy dissipation shows in Eq. (1), which are the height of spillway step and sill $(H$, $h, K)$ respectively, the length of the spillway, step and sill $(B, L, b)$ respectively, slope of the spillway $(S)$, number of steps $(N)$, Roughness height $(K s)$, acceleration gravity $(g)$ and unit discharge over stepped spillways (q).

$\frac{\Delta E}{E_{0}}=f\left(H, h, K, S, B, L, b, N, K_{s}, g, q\right)$

Using the dimensional analysis of the variables, the equation above is redesign as follows in Eq. (2) and for the non-marginal variables affecting the energy dissipation.

$\frac{\Delta E}{E_{0}}=f\left(\frac{H}{k s}, \frac{h}{k s}, \frac{L}{k s}, \frac{B}{k s}, F r, N, \frac{K}{k s}\right)$

where friction Froude number is known as shows in Eq. (3), while $(K s)$ define as the roughness height shows in Eq. (4).

$$
F r=\frac{q}{\sqrt{g \times \sin S \times k s^{3}}}
$$

$k s=h \times \cos S$

\section{RESULTS AND DISCUSSION 4.1. Verification of Flow-3D using Experimental Data}

In order to evaluate the accuracy of the analytical model, a comparison is made between the amount of energy dissipation in the experimental results of (Kurukji [17]) and data obtained by Flow-3D for model (1) under the same conditions, Table 1 shows a good degree of compatibility in the results for the different cases of flow over the stepped spillway which including three types (nappe, transition and skimming flow) depending mainly on the amount of discharge and the geometry of spillway. It is noticeable that the largest value of error is in the third case with the amount of $(8.55 \%)$ while the lowest error value is for the last case with the amount of $(0.51 \%)$.

Table 1

Comparison of the energy dispersion results obtained in the experimental results of Kurukji [17] and Data obtained by Flow-3D for model (1).

\begin{tabular}{cccc}
\hline Error\% & $\begin{array}{c}\mathbf{\%} \Delta \mathbf{E} / \mathbf{E}_{\mathbf{o}} \\
\text { (kurukji [17]) }\end{array}$ & $\begin{array}{c}\mathbf{\%} \Delta \mathbf{E} / \mathbf{E}_{\mathbf{o}} \\
\text { Flow-3D }\end{array}$ & $\begin{array}{c}\mathbf{Q} \\
\mathbf{c m}^{\mathbf{3}} / \mathbf{s e c}\end{array}$ \\
\hline 4.73 & 86.02 & 90.30 & 1956 \\
5.81 & 81.77 & 86.81 & 10164 \\
8.55 & 78.74 & 86.11 & 18229 \\
5.96 & 77.45 & 82.36 & 26219 \\
-2.83 & 76.52 & 74.41 & 27221 \\
0.51 & 73.59 & 73.96 & 38183 \\
\hline$H=45 \mathrm{~cm}, S=0.5, N=9, B=90 \mathrm{~cm}$, & \\
$L=10 \mathrm{~cm}, h=5 \mathrm{~cm}, b=1 \mathrm{~cm}, k=1 \mathrm{~cm}$, & \\
Flume width $81 \mathrm{~cm}$ &
\end{tabular}

\subsection{Factors Effecting the stepped Spillways Energy Dissipation Ratio ( $\triangle E / E 0)$}

One of the highest purposes of this research is to determine the effect of dimensionless parameters in Eq. (2) on the energy dissipation ( $\left.\Delta \mathrm{E} / \mathrm{E}_{0}\right)$ for stepped spillway with different geometric shape.

The three models have the same general variability in the relationship between the variables with the geometric effect. Therefore, the effect of the first model will be discusse on the variables of the geometrical dimensionless variable. The friction Froude number dimensionless variable is the most influential parameter on energy dissipation for model (3), as will be proven later on the artificial neural network so will be discussed this variable effect in expand way for models in this research.

\subsection{Effect of $(\mathrm{H} / \mathrm{ks})$ to the Energy Dissipation Ratio $\left(\Delta E / E_{0}\right)$}

Variation of $\left(\Delta E / E_{0}\right)$ with $\left(H / k_{s}\right)$ for model (1) of stepped spillway is shown in Fig. 5. From this figure may perceive that for the same discharge over spillway, constant height of spillway and different $(S)$ value the increase in $\left(H / k_{s}\right)$ value causes a decrease in $\left(\Delta E / E_{0}\right)$ value, and it was agree with [5], this could be assign to the reason that as the $\left(\mathrm{H} / \mathrm{k}_{\mathrm{s}}\right)$ increases the length of step decrease thus decrease the path flow over steps and decreasing the energy dissipation It is also observe that by increasing the amount of discharge over spillways the value of energy dispersion was decrees, this agree with [4,5,14]. In figure it also notices the amount of variation in the reduction of energy dissipation at the same discharge, where energy dissipation is reduced by about $30 \%$ when change the slope of spillway from (0.5-1.25) with using 18 steps, and $4 \%$ when using (6) steps for spillway. Also shows the highest value of energy dissipation develops at discharge $3 \mathrm{~L} / \mathrm{sec}$ is more than the highest value of energy dissipation at discharge $7 \mathrm{~L} / \mathrm{sec}$ about $9.5 \%$ when $(N=8)$, and about $10 \%$ when $(N=6)$.
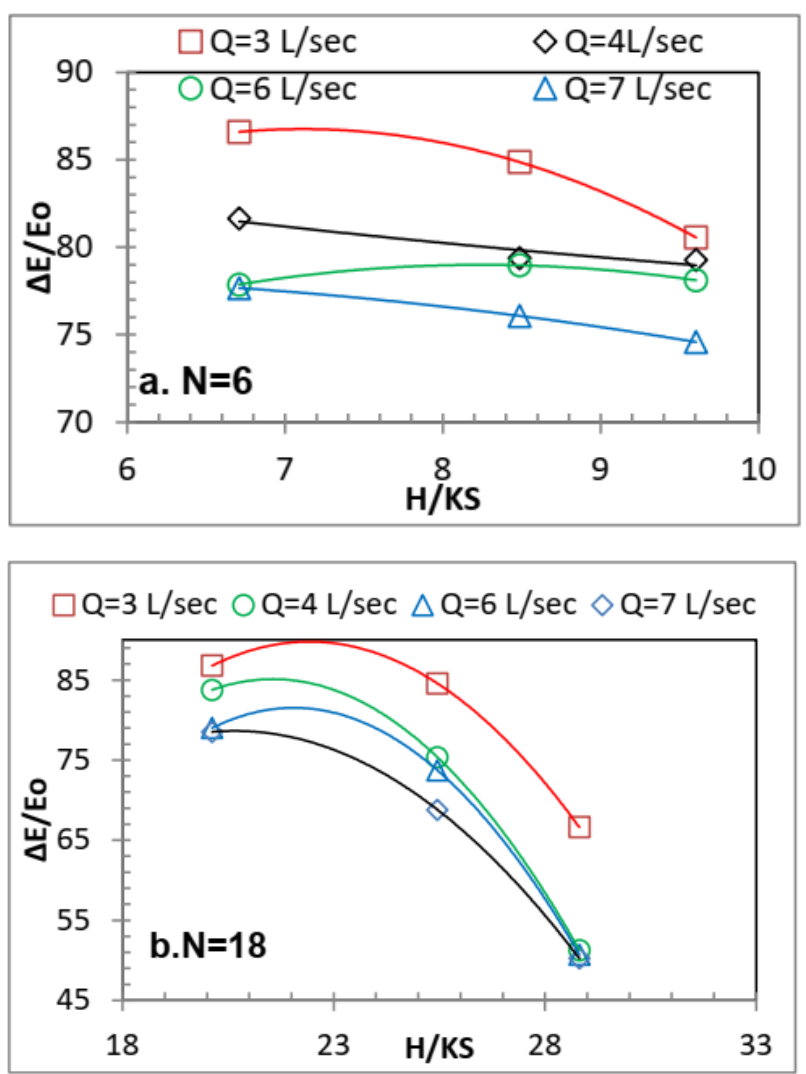

Fig. 5. Relation between energy dissipation and $(H / \mathrm{ks})$ for model (1), $(H=25 \mathrm{~cm}, k=0.5 \mathrm{~cm}, b=0.2 \mathrm{~cm})$. 


\subsection{Effect of $\left(h / k_{s}\right)$ to the Energy Dissipation Ratio $\left(\Delta E / E_{0}\right)$}

Fig. 6 shows the variation of $\left(\Delta \mathrm{E} / \mathrm{E}_{0}\right)$ with $\left(\mathrm{h} / \mathrm{k}_{\mathrm{s}}\right)$ for model (1) of stepped spillway. From this figure may observed that for the same discharge over spillway, and constant height of spillway, the increase in $\left(h / k_{s}\right)$ value causes a decrease in $\left(\Delta \mathrm{E} / \mathrm{E}_{0}\right)$ value, and it is agreeing with [14], this can be specifying to the reason that as the $\left(h / k_{s}\right)$ increases for the constant height of spillway the length of step decrease thus decrease the path flow over steps and decreasing the energy dissipation. It is also observing that by increasing the amount of discharge over spillways the value of energy dispersion is decrees, this agrees with $[4,5,14]$. In figure it also notes the amount of variation in the decrees of energy dissipation at the matching discharge, when $(h / k s)$ is increased by $20 \%$, the energy dissipation will be reducing by about $7 \%$ when using (6) steps and about $15 \%$ when using (12) steps for the spillway. Also show the highest value of energy dissipation develops at discharge $3 \mathrm{~L} / \mathrm{sec}$ is more than the highest value of energy dissipation at discharge $7 \mathrm{~L} / \mathrm{sec}$ about $14.4 \%$ when $(N=12)$, and about $12 \%$ when $(N=6)$.
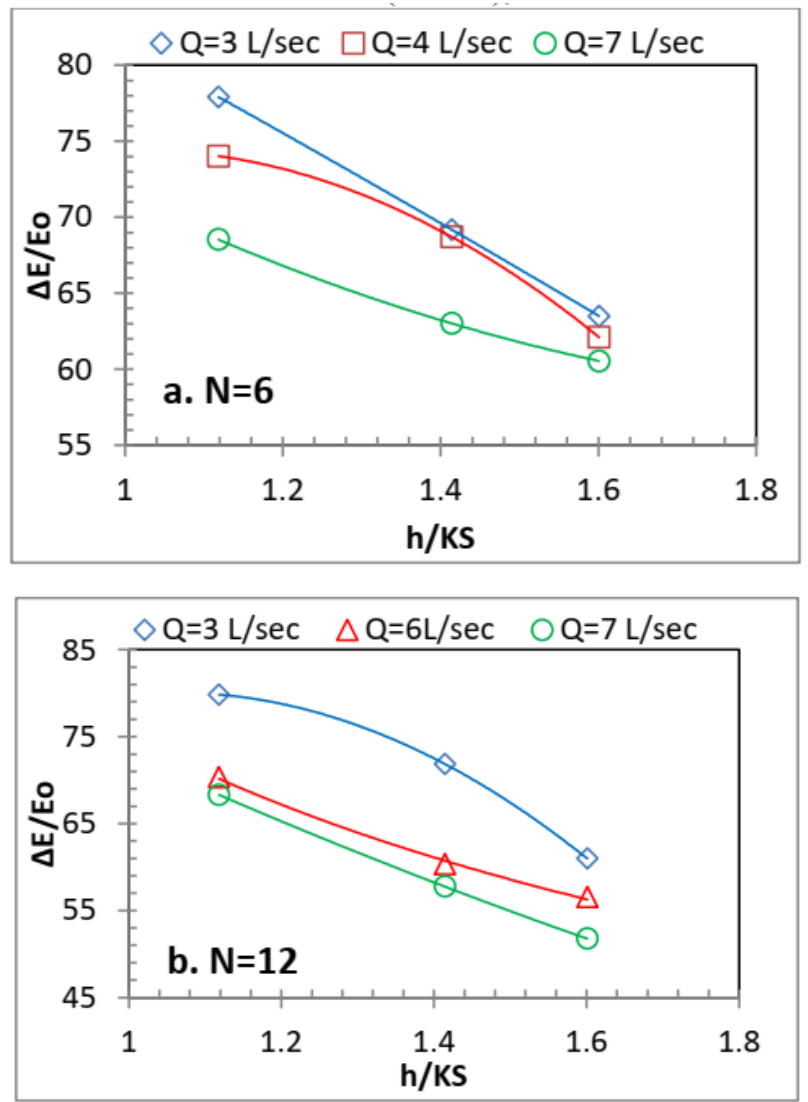

Fig. 6. Relation between energy dissipation and $(h / k s)$ for model (1), $(H=15 \mathrm{~cm}, k=0.5 \mathrm{~cm}, b=0.2 \mathrm{~cm})$.

\subsection{Effect of $\left(L / k_{s}\right)$ to the Energy Dissipation Ratio ( $\triangle E / E O)$}

The results are obtaining also show that variation of $\left(\Delta E / E_{0}\right)$ with $(L / k s)$ for model (1) of stepped spillway in Fig. 7. It is noticeable that the increase in the value of $\left(L / k_{s}\right)$ causes an increase in the value of $\left(\Delta E / E_{0}\right)$ and this is consistent. In figures it also observes that the amount of difference in energy dissipation increases at constant discharge, when increases $(L / k s)$ by $1 \%$ causes increasing in energy dissipation about $(0.15-0.43) \%$ by using (6) steps, and about $0.55 \%$ when using (12) steps for spillway. It's also observe that increase discharge leads to reduce energy dissipation.
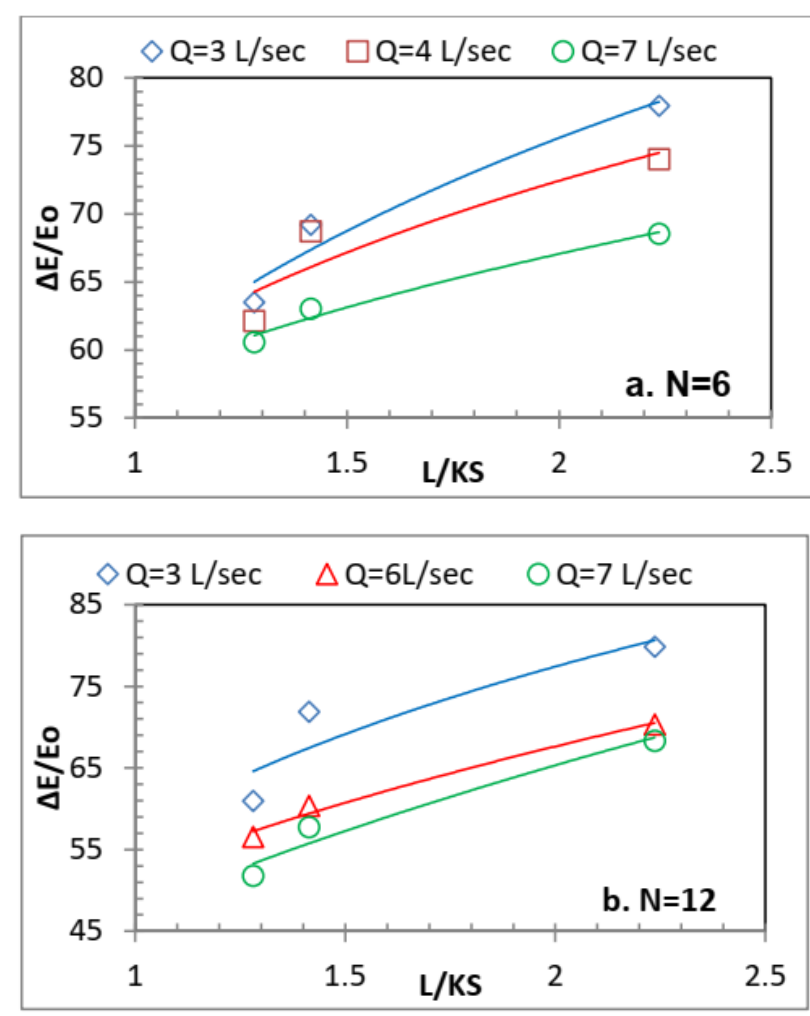

Fig. 7. Relation between energy dissipation and $(L / \mathrm{ks})$ for model (1), $(H=15 \mathrm{~cm}, k=0.5 \mathrm{~cm}, b=0.2 \mathrm{~cm})$.

\subsection{Effect of (Fr) to the Energy Dissipation Ratio $\left(\Delta E / E_{0}\right)$}

As shown in, Fig. 8 the effect of variation in the friction Froude number on energy dissipation of stepped spillways with rectangular and triangular sills on all steppes. It has been observed that the increase in friction Froude number causes a decrease in the rate of energy dissipation in all cases and for the models $(1 \& 3)$. Also the amount of $\left(\Delta E / E_{0}\right)$ for the model (3) is higher than model (1) and for most cases in range of (0.4-12)\%, also shows that for model (1), when the amount of $(S)$ changes from $(0.5-1.25)$ the result of $\left(\Delta E / E_{0}\right)$ decreases in ranges (2$47) \%$, this difference in the drop is due to increasing the amount of discharge and hence decrease (S) will lead to an increase in the dispersion of high discharge. While for model (3), when the amount of $(S)$ changes from $(0.5$ $1.25)$, the result of $\left(\Delta E / E_{0}\right)$ decreases in ranges $(9-37) \%$, this difference in the drop is due to increasing the amount of discharge over stepped spillways. It also observes from figure that by increasing the height of steps (h), for constant slope (S) and a certain amount of discharge, the dispassion at $(N=6)$ is higher than that of the $(N=12)$ and $(N=25)$.

\subsection{Variation in Energy Dissipation Ratio $(\Delta E / E O)$ between Model (1) and Model (2)}

Comparing the amount of energy dissipation between the first and the second models, it's observes that when the experiments are carried out an increases in the difference of energy dissipation about $8.7 \%$ for the second model 
(containing sill between one and other steps) comparing with the first model (containing sill in all steps) at the low discharges but when increasing the amount of discharges causes the increase in the effect of the air pockets led to decrease in the energy dissipation obtain by the second model at a rate of $(-5 \%)$ comparing to the first model. Fig. 9 shows random models results at the same geometry conditions for low and high discharges of the first and second models.
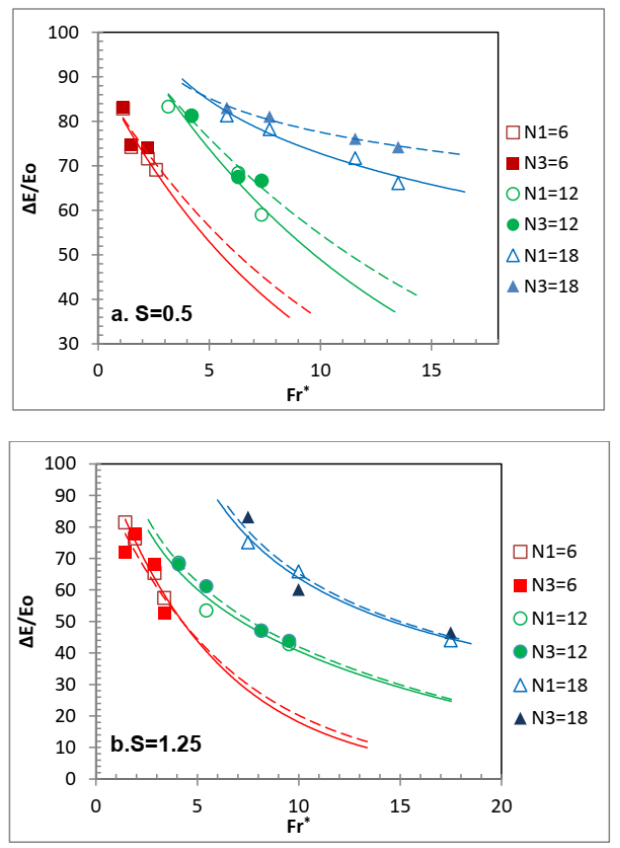

Fig. 8. Relation between energy dissipation and $(F r)$ for models (1\&3), $(H=20 \mathrm{~cm}, k=0.5 \mathrm{~cm}, b=0.2 \mathrm{~cm})(N 1$,

$N 3=$ no. of steps for models $(1 \& 3)$ respectively $)$.

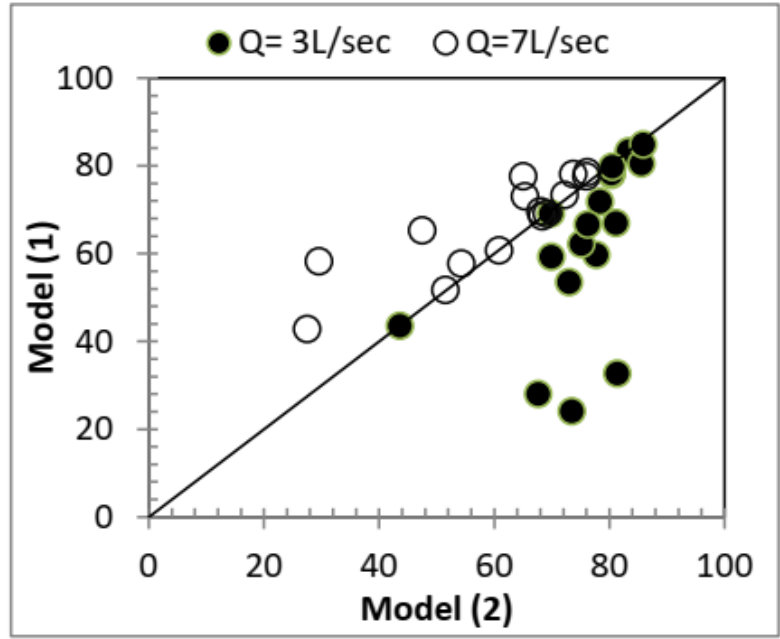

Fig. 9. Comparison between energy dissipation for stepped spillways Models (1\&2).

\subsection{Regression Analyses of Energy Dissipation for Stepped Spillways}

Data for which the dimensional analysis is carried out, $70 \%$ of which are enter into the statistical program (SPSS) to determine the general equation represents the amount of energy dissipation over stepped spillway containing rectangular end sills in all steps Eq. (5), rectangular end sills between one and other Eq. (6) and triangular end sills Equation in all steps of it, the coefficient of determination for Eqs. (5)-(7) equal to 0.74, 0.7 and 0.78 , respectively.

$\frac{\Delta E}{E_{0}}=221.766+4.847 \frac{H}{k s}-70.473 \frac{h}{k s}-29.713 \frac{L}{k s}+2.462 \frac{B}{k s}+0.06 F r-9.173 N-65.867 \frac{K}{K s}$

$\frac{\Delta E}{E_{0}}=220.68+4.847 \frac{H}{k s}-58.41 \frac{h}{k s}-42.74 \frac{L}{k s}+3.821 \frac{B}{k s}-1.607 F r-11.348 N-19.051 \frac{K}{K s}$

$\frac{\Delta E}{E_{0}}=139.955+0.237 \frac{H}{k s}-31.413 \frac{h}{k s}-14.520 \frac{L}{k s}+0.887 \frac{B}{k s}-1.626 F r-1.201 N-0.558 \frac{K}{K s}$

Table 2

The effect of data dividing on the performance of the neural network model for stepped spillway (Model 1).

\begin{tabular}{|c|c|c|c|c|c|c|}
\hline \multicolumn{2}{|c|}{ Data division (\%) } & \multicolumn{2}{|c|}{ Training error $(\%)$} & \multicolumn{2}{|c|}{ Testing error $(\%)$} & \multirow[b]{2}{*}{$\begin{array}{l}\text { Coefficient of } \\
\text { correlation } \\
\left(\mathbf{R}^{2}\right) \%\end{array}$} \\
\hline $\begin{array}{l}\text { Training } \\
(\%)\end{array}$ & $\begin{array}{l}\text { Testing } \\
(\%)\end{array}$ & $\begin{array}{l}\text { Sum of } \\
\text { squares } \\
\text { error }\end{array}$ & $\begin{array}{l}\text { Relative } \\
\text { error }\end{array}$ & $\begin{array}{l}\text { Sum of } \\
\text { squares } \\
\text { error } \\
\end{array}$ & $\begin{array}{l}\text { Relative } \\
\text { Error }\end{array}$ & \\
\hline 76.4 & 23.6 & 38.4 & 19.8 & 19.2 & 37.8 & 87.6 \\
\hline 70.8 & 29.2 & 16 & 10.4 & 11.6 & 19.8 & 93.3 \\
\hline 72.6 & 27.4 & 26.1 & 12.5 & 53.1 & 40 & 87.8 \\
\hline 63.2 & 36.8 & 20.3 & 16 & 43.8 & 36.6 & 86.1 \\
\hline 65.1 & 34.9 & 20.2 & 15.5 & 7.6 & 9.2 & 93.4 \\
\hline
\end{tabular}


The remaining $30 \%$ of the data are testing of the equations and a comparison of these results is drawn to those calculate from the suggest equations as show in Figs. 10 and Fig. 11.

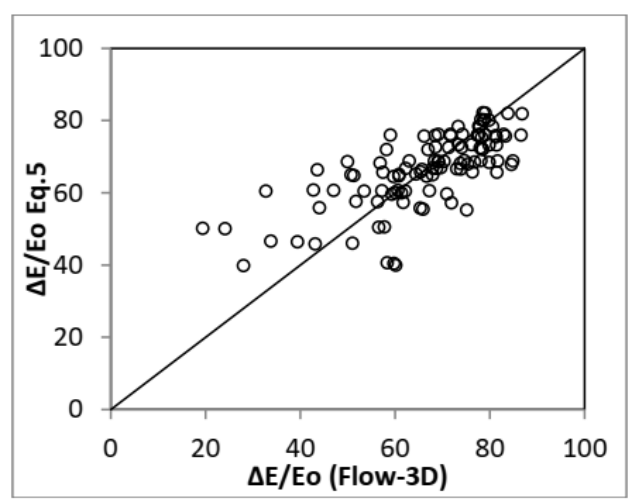

Fig. 10. Comparison between energy dispersion by flow-3D and the propose Eq. (5), for model (1).

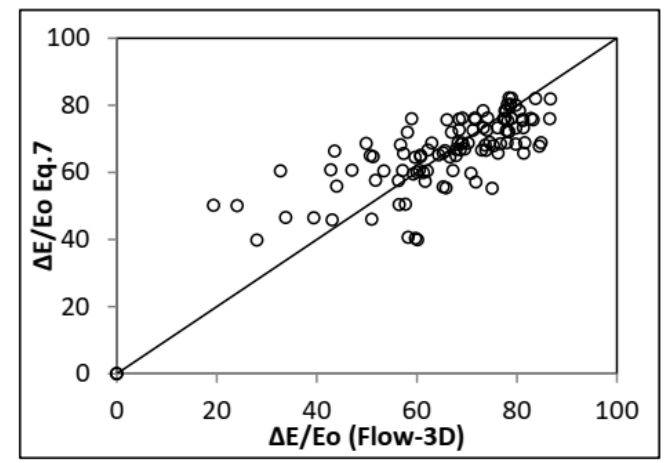

Fig. 11. Comparison between energy dispersion by flow-3D and the propose Eq. (7), for model (3).

\subsection{Constructing Artificial Neural Network Models}

The methodology used in building artificial neural network model develop in this research involves the development of a set of Sub-models, such as the input layer, hidden layer, and output layer. The number of nodes in the input layer represents all the variables affecting the energy dissipation, while the output layer consists of a single node represent by energy dissipation, however the selection of the number of nodes in the hidden layer represents the important part in determining the accuracy of this (ANN) model where the choice of the optimal number depends on the total error in training and testing data, in addition to the coefficient of correlation. Selecting the optimal number of nodes in the hidden layer as well as the weights connecting this layer with the input and output layer depends on the trial and error so the best neural network model is obtain.

Statistic consistent methods are using for the purpose of distributing data into the two groups (the training group, and the testing group), the positives of this method are reliant on trial and error mode to get the best ANN model, Table 2 shows the influence of data dividing on the performance of the network model.

From the table, it's observe that the best division of data is $65.1 \%$ for training and $34.9 \%$ for testing, which depending on the lowest error rate and the highest coefficient of correlation.

Fig. 12 shows that there is a difference in the error ratio of the test group and the best performance of the network when the number of nodes in hidden layer equal to five. Thus, the typical form of this network develop in this paper is three neural layers (input layer, hidden layer with five nodes and output layer with one node) as show in Fig. 13 and Eqs. (8)-(10).

$$
\begin{aligned}
& \frac{\Delta E}{E_{0}}\left(\text { for model 1) }=f_{\text {of Independent Variables }}\left(\frac{H}{k s}, \frac{h}{k s}, \frac{L}{k s}, \frac{b}{k s}, F r, N, \frac{K}{k s}, \frac{Y_{0}}{k s}, \frac{Y_{1}}{k s}\right)\right. \\
& \frac{\Delta E}{E_{0}}\left(\text { for model 2) }=f_{\text {of Independent Variables }}\left(\frac{H}{k s}, \frac{h}{k s}, \frac{L}{k s}, \frac{b}{k s}, F r, N, \frac{Y_{0}}{k s}, \frac{Y_{1}}{k s}\right)\right. \\
& \frac{\Delta E}{E_{0}}\left(\text { for model 3) }=f_{\text {of Independent Variables }}\left(\frac{H}{k s}, \frac{h}{k s}, \frac{L}{k s}, \frac{B}{k s}, F r, N, \frac{K}{k s}, \frac{b}{k s}\right)\right.
\end{aligned}
$$

where $\mathrm{Y}_{0}$ and $Y_{1}$ represent the water level at upstream and toe of spillway respectively.

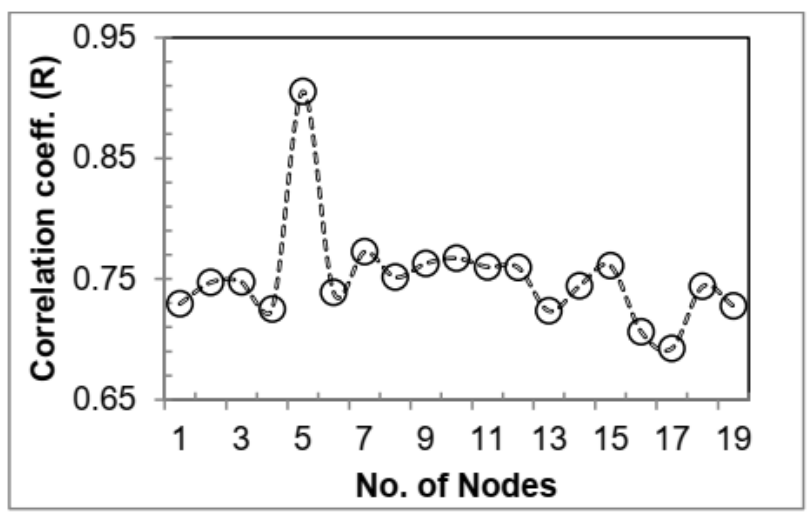

Fig. 12. Performance of artificial neural network model with different number of nodes.

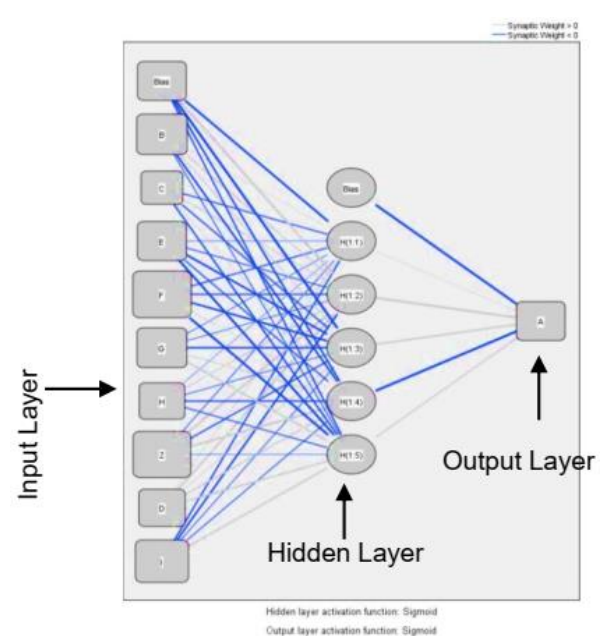

Fig. 13. The artificial neural network developed in this research, model (1). 
The performance of the ANN model for calculating energy dissipation over stepped spillways are comparing with Flow-3D results at the same boundary conditions for models (1), (2) and (3) as shown in Figs. (14)-(16), respectively. This comparison shows high accuracy in the convergence of results and this indicates the efficacy of the propose artificial neural network for predicting the amount of energy dissipation over stepped spillways.

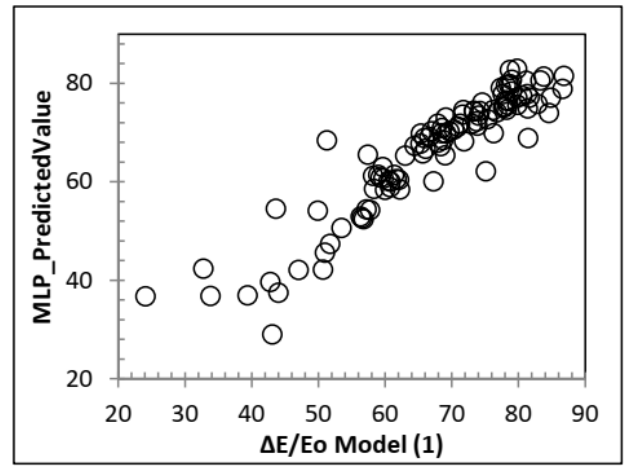

Fig. 14. Comparison between energy dispersion by flow3D and the MLP predict value, for model (1).

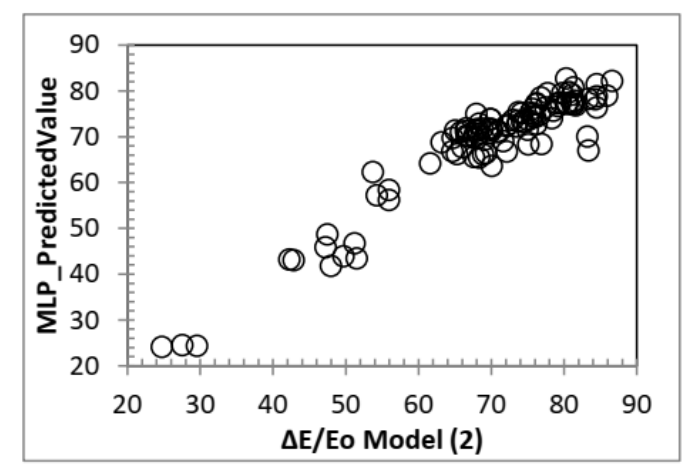

Fig. 15. Comparison between energy dispersion by flow3D and the MLP predict value, for model (2).

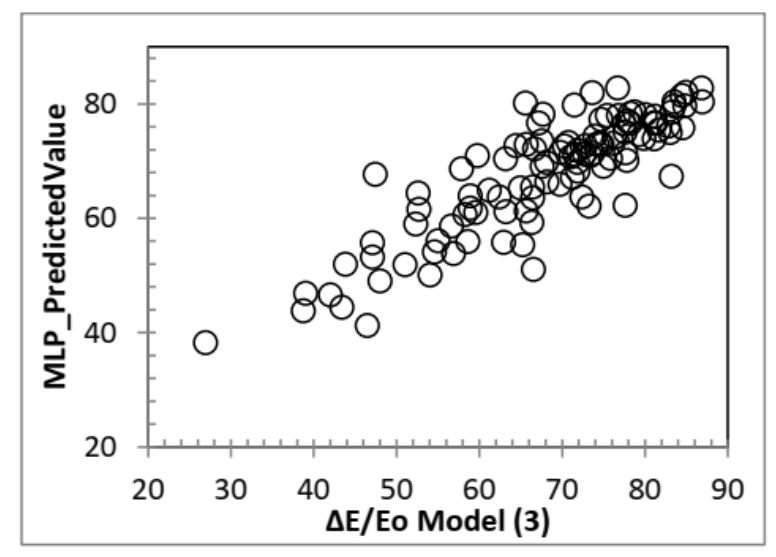

Fig. 16. Comparison between energy dispersion by flow$3 \mathrm{~d}$ and the MLP predict value, for model (3).

\subsection{Validation for Regression and ANN Models}

In this research, the statistical standard: coefficient of correlation, mean absolute percentage error and average accuracy percentage are used to prove the efficiency of the regression analysis of models $(1,2,3)$, and results from artificial neural network models that develop in this research. Table 3 shows the results of statistical standard for models which have a very high accuracy score.

\subsection{Independent Variable Importance Using (ANN)}

Table 4 illustrates the importance of variables affecting the amount of energy dissipation depending on the results of artificial neural network, where the importance of the parameters $(F r)$ is most influential for models (2) and (3), and (b/Ks) for model (1).

Table 3

Validation models.

\begin{tabular}{|c|c|c|c|c|c|c|}
\hline \multicolumn{3}{|c|}{ Statistical values of ANN model } & \multicolumn{3}{|c|}{ Statistical values of Regression Analysis } & \multirow[b]{2}{*}{$\begin{array}{l}\text { Statistical } \\
\text { standards }\end{array}$} \\
\hline $\begin{array}{l}\text { Average } \\
\text { Accuracy } \\
\text { Percentage } \\
(\text { AA\%) }\end{array}$ & $\begin{array}{l}\text { Mean } \\
\text { Absolute } \\
\text { Percentage } \\
\text { Error } \\
\text { (MAPE) \% }\end{array}$ & $\begin{array}{l}\text { The Coefficient } \\
\text { of Correlation } \\
\text { (R) } \%\end{array}$ & $\begin{array}{l}\text { Average } \\
\text { Accuracy } \\
\text { Percentage } \\
(\text { AA\%) }\end{array}$ & $\begin{array}{l}\text { Mean } \\
\text { Absolute } \\
\text { Percentage } \\
\text { Error } \\
\text { (MAPE)\% }\end{array}$ & $\begin{array}{l}\text { The } \\
\text { Coefficient of } \\
\text { Correlation } \\
\text { (R) } \%\end{array}$ & \\
\hline 93.59 & 6.41 & 93.47 & 90.10 & 9.90 & 71.3 & 1 \\
\hline 89.70 & 10.30 & 88.20 & 80.29 & 19.71 & 70.0 & 2 \\
\hline 92.24 & 7.76 & 86.00 & 93.65 & 6.35 & 75.8 & 3 \\
\hline
\end{tabular}

\section{CONCLUSIONS}

The current study is aimed to measure the amount of energy dissipation for stepped spillways with rectangular and triangular end sills for all steps, as well as the case of the rectangular end sills between one and other steps. The following conclusions have been reached:

1. The effectiveness of Flow-3D software in the representation of energy dissipation, where the error rate is found when compared with the practical results $(8.55-0.51) \%$ which is a good ratio.
2. The amount of energy dissipation of the model containing the triangular end sills for all steps is greater than that of other models in research.

3. The dispersion of the model with end sills between one and the other steps is more efficient at low discharges, and less efficient at high discharges, compared to the model with rectangular end sills for all steppes.

4. Empirical equations are found to calculate energy dissipation for all models, with a coefficient of determination for (model 1), (model 2) and (model 3) equal to $0.74,0.7$ and 0.78 respectively.

5. Efficient use of the artificial neural network in the representation of energy dissipation of the three models, with a coefficient of determination for (model 
1), (model 2) and (model 3) equal to $93.47 \%, 88.20 \%$ and $86.00 \%$ respectively.

6. Using ANN help to find the importance of the variables involve in the calculation of the amount of energy dissipation, where the results show that the friction
Froude number was the highest impact on the energy dissipation for models (2) and (3), and the parameter $(b / k s)$ for the model (1).

Table 4

Variables Importance for energy dissipation.

\begin{tabular}{|c|c|c|c|c|c|c|c|c|}
\hline \multicolumn{3}{|c|}{ Model (3) } & \multicolumn{3}{|c|}{ Model (2) } & \multicolumn{3}{|c|}{ Model (1) } \\
\hline $\begin{array}{l}\text { Normalized } \\
\text { Importance } \\
(\%)\end{array}$ & Importance & $\begin{array}{l}\text { Independent } \\
\text { Variable }\end{array}$ & $\begin{array}{l}\text { Normalized } \\
\text { Importance } \\
(\%)\end{array}$ & Importance & $\begin{array}{l}\text { Independent } \\
\text { Variable }\end{array}$ & $\begin{array}{l}\text { Normalized } \\
\text { Importance } \\
(\%)\end{array}$ & Importance & $\begin{array}{l}\text { Independent } \\
\text { Variable }\end{array}$ \\
\hline 30.7 & 0.094 & $H / k s$ & 31.7 & 0.064 & $H / k S$ & 59.5 & 0.114 & $H / k s$ \\
\hline 16.6 & 0.051 & $h / k s$ & 94.3 & 0.189 & $h / k s$ & 13.4 & 0.026 & $h / k s$ \\
\hline 29.7 & 0.091 & $L / k s$ & 42.9 & 0.086 & $L / k s$ & 51.0 & 0.098 & $L / k s$ \\
\hline 34.1 & 0.104 & $b / k s$ & 36.8 & 0.074 & $b / k S$ & 100 & 0.192 & $b / k s$ \\
\hline 33.6 & 0.103 & $k / k s$ & 46.6 & 0.094 & $N$ & 55.8 & 0.107 & $K / k s$ \\
\hline 100 & 0.306 & $F r$ & 100 & 0.201 & $\boldsymbol{F r}$ & 33.7 & 0.065 & $F r$ \\
\hline 16.8 & 0.051 & $N$ & 46.9 & 0.094 & $Y 0 / K S$ & 96.9 & 0.189 & $N$ \\
\hline 65.4 & 0.200 & $B / k s$ & 99.2 & 0.199 & $Y 1 / K S$ & 38.3 & 0.073 & $Y_{0} / \mathrm{ks}$ \\
\hline & & & & & & 72.2 & 0.139 & $Y_{1} / k s$ \\
\hline
\end{tabular}

\section{REFERENCES}

[1] Rassaei M, Rahbar S. Study and comparison of the rate of energy dissipation in stepped overflows before and after hydraulic jump using laboratory model. IOSR Journal of Engineering 2014; 4: 30-33.

[2] Roshan R, Azamathulla H, Marosi M, Sarkardeh H, Pahlavan H, Ab Ghani A. Hydraulics of stepped spillways with different numbers of steps. Dams and Reservoirs 2010; (3): 131-136.

[3] Al- Husseini TR. Experimental study of increasing energy dissipation on stepped spillway. Journal of Kerbala University 2015; 13: 87-100.

[4] Shahheydari H, Nodoshan EJ, Barat R, Moghadam MA. Discharge coefficient and energy dissipation over stepped spillway under skimming flow regime. KSCE Journal of Civil Engineering 2014: 1-9.

[5] Irzooki RH, Mohammed JR, Ameen AS. Computational fluid dynamics modeling of flow over stepped spillway. Tikrit Journal of Engineering Sciences 2016; 23: 1-11.

[6] Patil LG, Jadhav SS. Performance evaluation of stepped spillway under nappe flow condition. International Advanced Research Journal in Science, Engineering and Technology 2017; 4: 111-114.

[7] Vosoughifar HR, Dolatshah A, Shokouhi SK, Nezhad SR. Evaluation of fluid flow over stepped spillways using the finite volume method as a novel approach. Journal of Mechanical Engineering 2013; 59: 301310.

[8] Chakib B, Mohammed H. Numerical simulation of air entrainment for flat-sloped stepped spillway. Journal of Computational Multiphase Flows 2015; 7: 33-41.

[9] Hamedi A, Ketabdar M. Energy loss estimation and flow simulation in the skimming flow regime of stepped spillways with inclined steps and end sill: A numerical model. International Journal of Science and Engineering Applications 2016; 5: 399- 407.
[10] Roushangar K, Akhgar S, Salmasi F, Shiri J. Modeling energy dissipation over stepped spillways using machine learning approaches. Journal of Hydrology 2014; 508: 254-265.

[11] Al-Shukur AK, Al-Khalaf SH, Al-sharifi IM. Study of optimum safe hydraulic design of stepped spillway by physical models. International Journal of Scientific \& Engineering Research 2014; 15: 13561365.

[12] Khalaf RM, Irzooki RI, Shareef SJ. Flow characteristics and energy dissipation over traditional and stepped spillway with semicircular crest. International Journal of Civil \& Environmental Engineering 2014; 14: 13-26.

[13] Al- Husseini TR. A Novel experimental work and study on flow and energy dissipation over stepped spillways. Journal of Babylon UniversityEngineering Sciences 2016; 24 (4): .

[14] Abdul-Mehdi TR, Al- Mussawy HA, Al-Madhhachi AT. A laboratory study attempt of flow and energy dissipation in stepped spillways. Journal of Engineering 2016; 22: 48-64.

[15] Maatooq JS. Kinetic energy dissipation on labyrinth configuration stepped spillway. Tikrit Journal of Engineering Sciences 2016; 23: 12-24.

[16] Jahad UA, Al-Amery R, Chua LH, Das S. Energy dissipation and geometry effects over stepped spillways. International Journal of Civil Engineering and Technology 2016; 7: 188-198.

[17] Kurukji EM. Experimental Study for Improving the performance of Stepped Spillway using an Obstructions", Al-Rafidain 2012; 20: 83-93.

[18] Al-Shukur AK, Al-Khalaf SK, Al-sharifi IM. Flow characteristics and energy dissipation losses in different configurations of steps of stepped spillway. International Journal of Innovative Research in Science, Engineering and Technology 2014; 3: 88238832 . 